\title{
Eutrophication and tidal marshes shape dissolved organic matter chemistry along two freshwater- estuarine transects
}

\author{
DING HE ${ }^{1,2, *}$, YANZHEN ZHANG ${ }^{1}$, QINGYUAN LU ${ }^{1}$, \\ PENGHUI $\mathrm{LI}^{3}$, CHEN HE${ }^{4}$, YUNT AO WANG ${ }^{2}$, QUAN SHI ${ }^{4}$, \\ YONGGE SUN ${ }^{1}$ \\ ${ }^{1}$ School of Earth Sciences, Zhejiang University, Hangzhou \\ 310027, China \\ ${ }^{2}$ State Key Laboratory of Satellite Ocean Environment \\ Dynamics, Second Institute of Oceanography, Ministry \\ of Natural Resources, Hangzhou 310012, China \\ ${ }^{3}$ Southern University of Science and Technology, Shenzhen \\ 518055, China \\ ${ }^{4}$ State Key Laboratory of Heavy Oil Processing, China \\ University of Petroleum, Changping District, Beijing \\ 102249, China
}

Although dissolved organic matter (DOM) plays a crucial role in the costal carbon cycle, how eutrophication and connected tidal marshes affects DOM cycling remains poorly understood in coastal rivers. In order to fill this knowledge gap, DOM composition was analyzed by a suite of bulk and optical techniques, and the Fourier transform ion cyclotron resonance mass spectrometry along two river-estuary transects in the Liao and Daliao rivers, Northeast China, with the similar geological background but different degree of eutrophic state and distribution of tidal marshes. Daliao River is characterized by higher eutrophication degree but surrounded with lower reed coverage than the Liao River. Significantly higher eutrophication status and dissolved organic carbon concentrations were observed in Daliao River than Liao River. Daliao River is characterized by relatively higher autochthonous DOM, supported by higher stable carbon isotope $\left(\delta^{13} \mathrm{C}\right)$ values, higher protein-like fluorescent components, and abundance of peptide and sugar-like compounds, than Daliao River. Associations between optical and molecular signatures revealed a humic-like component correlated with molecular formulae with lower molecular weight and aromaticity, and higher $\mathrm{H} / \mathrm{C}$, which likely is originated from phytoplankton but further reworked by active heterotrophic processing, indicating the production of algal bloom derived humic-like compounds. Reed could introduce a series of highly aromatic formulae to both rivers. Further principal component analysis confirmed that eutrophication and tidal marsh input both shape the DOM molecular composition and lability, which warrants further investigations considering the continued increase of worldwide eutrophication in estuaries. 